\title{
Prevention of Coronary Heart Disease: A Translational Clinical Challenge
}

\author{
Julie Giannini, Janae Padilla, Robert Philip Eaton, Kristen Gonzales, David S. Schade* \\ Department of Internal Medicine, Division of Endocrinology and Metabolism, University of New Mexico Health Sciences Center, \\ Albuquerque, USA \\ Email: *dschade@salud.unm.edu
}

How to cite this paper: Giannini, J., Padilla, J., Eaton, R.P., Gonzales, K. and Schade, D.S. (2022) Prevention of Coronary Heart Disease: A Translational Clinical Challenge. World Journal of Cardiovascular Diseases, 12, 11-23.

https://doi.org/10.4236/wjcd.2022.121002

Received: December 9, 2021

Accepted: January 18, 2022

Published: January 21, 2022

Copyright (C) 2022 by author(s) and Scientific Research Publishing Inc. This work is licensed under the Creative Commons Attribution International License (CC BY 4.0).

http://creativecommons.org/licenses/by/4.0/

\begin{abstract}
Introduction: Atherosclerotic cardiovascular disease is a dysmetabolic medical condition resulting in the \#1 cause of morbidity and mortality in the United States. Coronary Artery Calcium (CAC) CT non-invasively identifies atherosclerosis in asymptomatic individuals. This translational study tested the hypothesis that clinically overt cardiovascular disease can be prevented in asymptomatic individuals in a medical clinic. Methods: Two hundred and six asymptomatic adults requested a CAC scan to identify subclinical heart disease. Individuals with a positive CAC score $>1(n=125)$ were prescribed targeted medical therapy to reverse their atherosclerosis. The goal was to achieve an LDL Cholesterol (LDL-C) $\leq 60 \mathrm{mg} / \mathrm{dl}$. One hundred and ten individuals reached this goal (67 male, 43 female) receiving $10 \mathrm{mg} / \mathrm{d}$ of rosuvastatin and $10 \mathrm{mg} / \mathrm{d}$ of ezetimibe plus a low cholesterol diet. Other fifteen individuals with positive CAC scores did not achieve this LDL-C goal. Results: In the group following medical therapy and achieving an LDL-C $\leq 60 \mathrm{mg} / \mathrm{dl}$, no cardiovascular events were observed during a maximum observation period of 5 years (mean observation time $=3.6$ years). Based on previously published CVD outcome data in individuals with similar CAC scores, 12.6 cardiovascular events were expected. Two of fifteen individuals with positive CAC scores not following medical therapy had a cardiovascular event. None of the 81 individuals with a zero score had a cardiovascular event during follow-up. No adverse effects of therapy occurred. Conclusion: In a medical clinic, adult population with positive CAC scores and an LDL-C $\leq 60 \mathrm{mg} / \mathrm{dl}$, targeted medical therapy prevented overt cardiovascular disease. These results should encourage other physicians to aggressively treat atherosclerotic cardiovascular disease in their clinic populations.
\end{abstract}

\section{Keywords}

Asymptomatic Cardiovascular Disease, Coronary Artery Calcium Scan, Preventive Medical Therapy, Cardiovascular Risk 


\section{Introduction}

Atherosclerotic Cardiovascular Disease (CVD) is a dysmetabolic disease and prevention should be a primary focus for physicians. Not only is it the number one cause of morbidity and mortality in the United States, but it also has effective therapeutic options available. Both the widespread availability of the non-invasive Coronary Artery Calcium (CAC) scan to identify asymptomatic CVD and the availability of inexpensive medications to lower LDL Cholesterol (LDL-C) offer the promise to greatly reduce the mortality and cost of CVD [1] [2]. However, the clinical application of preventive therapies has not been demonstrated outside of the research setting. Under controlled conditions, research studies have demonstrated that the lower the plasma LDL-C, the fewer cardiovascular events are observed [3]. We performed a translational clinical study to test the hypothesis that CVD could be prevented in a medical clinic environment.

Since 2015, our medical clinic has been treating self-referred asymptomatic patients with positive CAC scans in order to delay and/or reverse asymptomatic CVD [4]. Our recommended goal is to make all patients achieve an LDL Cholesterol (LDL-C) $\leq 60 \mathrm{mg} / \mathrm{dl}$ following specific medical therapy. This goal is readily achievable in patients with an initial LDL-C $\leq 150 \mathrm{mg} / \mathrm{dl}$. This approach is a paradigm shift from treating atherosclerotic risk based solely on risk factors to that based on radiographically identifiable cardiac lesions. The patients in this retrospective observational study have been followed from approximately every four to six months to up to five years, in order to assess maintenance of the target of LDL-C $\leq$ $60 \mathrm{mg} / \mathrm{dl}$ and any new onset of symptomatic CVD including angina, myocardial infarction, atherosclerotic strokes, heart failure, and CVD death or death from nonCVD causes.

\section{Methods}

Between 2015 and 2021, 206 healthy adults, ages 28 to 87 requested a CAC scan. They had heard or read about the benefits of the coronary artery calcium scanning for predicting CVD from newspaper, television, lectures, social media or local radio broadcasts. Following the CAC scan, individuals with positive scans (Agatston scores $>1$ ) were seen in the medical clinics at the University of New Mexico Health Science Center. All subjects in this report were followed for at least 12 months and had a lipid profile measured prior to being seen in the clinic. After the first clinic visit, many also had a lipoprotein (a), a high sensitivity $\mathrm{C}$-reactive protein, and a hemoglobin $\mathrm{A} 1 \mathrm{C}$ measured. These plasma markers are additional risk factors for atherosclerosis [5] [6]. All subjects were asymptomatic at the time of their first clinic visit. Patients with diabetes, hypertension, or other medical conditions were treated for these conditions according to current national practice guidelines by their primary care provider. Patients with a $\leq 1 \mathrm{cal}-$ cium score were not followed-up further except to reschedule a repeat calcium scan in five years [7]. After the risks and benefits of treatment were discussed, individuals with a CAC scan score $>1$ Agatston units were prescribed rosuvastatin 
$10 \mathrm{mg} / \mathrm{d}$, ezetimibe $10 \mathrm{mg} / \mathrm{d}$, and a low cholesterol diet (Figure 1). The low cholesterol diet $(<200 \mathrm{mg}$ of cholesterol/day) facilitates the pharmacological effects of ezetimibe in lowering LDL-C [8]. It is also easily incorporated into the average American diet. The treatment goal was to reduce the patient's LDL-C to $\leq 60$ $\mathrm{mg} / \mathrm{dl}$ [9]. Compliance with medication was monitored with periodic review of the patients' medication refill requests and response to therapy. Follow-up visits including a lipid profile were scheduled every four to six months. This schedule was sometimes interrupted by the COVID-19 pandemic in which telemedicine visits were substituted for in-person clinic visits. All patients were encouraged to improve their lifestyle by getting more exercise, controlling their diabetes and hypertension, and to stop smoking. If the patients were on prescribed statins at the time of referral they were changed to rosuvastatin $10 \mathrm{mg} /$ day plus ezetimibe $10 \mathrm{mg} / \mathrm{d}$.

The decision not to treat individuals with a $\leq 1$ CAC score was based on numerous studies of healthy long-term outcomes in these individuals [10]. There is a direct correlation between the extent of coronary calcification and the burden of atherosclerotic plaque [11]. The expert consensus statement from the Society of Cardiovascular Computed Tomography emphasizes that patients with a zero CAC score may prefer to defer statin therapy and repeat the exam in four to five years [12].

In order to assess the success or failure of our approach to reducing cardiac events, we relied on studies that reported cardiovascular events based on CAC scores. The main advantage of this approach is that sufficient numbers of cardiovascular

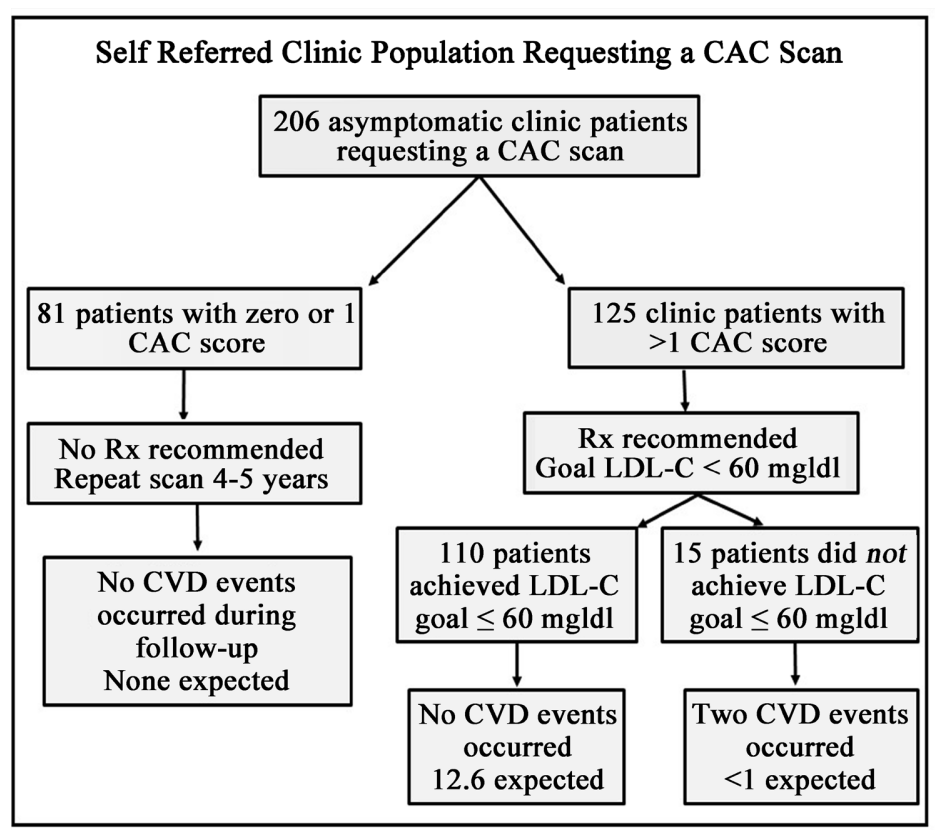

Abbreviations: $\mathrm{CAC}=$ coronary artery calcium scan; $\mathrm{Rx}=$ targeted medical treatment; $\mathrm{CVD}=$ cardiovascular; LDL-C = low density lipoprotein cholesterol.

Figure 1. Disposition of 206 self-referred individuals following a coronary artery calcium scan. Three groups of adults were identified and followed for up to five years. 
events can be observed in a short period of time because all patients with positive CAC scores are at imminent increased risk of a cardiovascular event. The predictive number of CVD events in our patient cohort with a positive CAC scan is based on three published population-based annual event rates in asymptomatic patients undergoing CAC testing [13] [14] [15]. In the population-based Rotterdam study of 1795 participants with a mean age of 71 years (range 62 to 85 years), CAC testing was performed and the individuals were followed for a mean of 3.3 years [13]. The event rates for scores between 400 and 1000 and for scores $>1000$ (Table 1) were applied to the current study. The event rate for scores $<400$ were not used because the scores from $0-100$ in that study were arbitrarily grouped together, preventing the separation of individuals with a zero score. For scores below 400, the CVD event data were obtained from the MESA population database [14]. This population-based study of 6603 individuals was followed for a median of 6.4 years. Their annualized CVD event rate was divided into individuals free of diabetes and metabolic syndrome, individuals with the metabolic syndrome, and individuals with diabetes. They divided their scores into zero, 1 to 99,100 to 399 , and $>400$. Their event rate for individuals with a CAC score of $>400$ was 2.6 CVD events per year which is similar to the Rotterdam study of CAC scores $>400$ of 2.9 events per year [13]. In addition, if an individual patient had either diabetes or the metabolic syndrome, the estimated increased risk for a CVD event was based on the data of Malik [15]. We did not further adjust our rates based on other risk factors such as age, ethnicity, gender, etc. because the specific annualized increase (or decrease) could not be estimated from the published data when the individual risk factors were grouped together [15]. Based on the following factors, an expected occurrence of a cardiovascular event was calculated utilizing: 1) the CAC score; 2) the duration of follow-up; 3) the presence or absence of diabetes (A1C $>6.5$ or diabetic medications); and 4) the presence or absence of the metabolic syndrome.

Coronary Artery Calcium (CAC) scanning was assessed by chest CT using 3

Table 1. Coronary artery calcium score with risk factor.

\begin{tabular}{ccccc}
\hline & \multicolumn{4}{c}{ CVD Risk Factor } \\
\cline { 2 - 5 } & $\mathbf{1 - 9 9}$ & $\mathbf{1 0 0 - 3 9 9}$ & $\mathbf{4 0 0 - 1 0 0 0}$ & $>\mathbf{1 0 0 0}$ \\
\hline None & $0.7 \%$ & $1.7 \%$ & $2.6 \%$ & $5.2 \%$ \\
Met Syndrome $^{*}$ & $1.2 \%$ & $2.4 \%$ & $4.6 \%$ & $9.2 \%$ \\
Diabetes $^{* *}$ & $2.2 \%$ & $2.9 \%$ & $5.1 \%$ & $10.2 \%$ \\
\hline
\end{tabular}

*The metabolic syndrome was based on having at least three of the following characteristics: 1) obesity (BMI > 30); 2) an HDL cholesterol $<40 \mathrm{mg} / \mathrm{dL}$ for men or $<50 \mathrm{mg} / \mathrm{dL}$ for women; 3) fasting triglycerides $>150 \mathrm{mg} / \mathrm{dL}$; 4) hypertension (systolic $>130 \mathrm{mmHg}$ or diastolic $>80 \mathrm{mmHg}$ or on hypertension treatment; or 5$)$ diabetes $(\mathrm{A} 1 \mathrm{C}>6.5 \%$ or on diabetes medications). However, if a patient had both the metabolic syndrome and diabetes, the data were analyzed as having diabetes. ${ }^{*}$ Diabetes was defined as an $\mathrm{A} 1 \mathrm{C}>6.5 \%$, a fasting glucose $>125 \mathrm{mg} / \mathrm{dl}$, or taking diabetic medications. This table was derived from data provided from references [13] [14] [15]. 
$\mathrm{mm}$ increments of a cardiac-gated multi-detector CT Siemans Definition system (Siemans, Washington DC). A CT certified technologist scanned all participants over phantoms of known calcium concentration. At least two adjacent pixels with a density $>130$ Hounsfield units were required to define a lesion. A radiologist read all computed tomography scans. A1C was measured by electrophoresis using a Tera 3 instrument (Sebia, Norcross, GA). Lipoprotein (a) was assayed by quantitative nephelometry (Siemans BM2, Washington DC). HsCRP and lipid profiles were measured by nephelometric assay on a Siemans Dimension Vista (Siemans, Washington DC). LDL-C was calculated with the Freidewald equation [16]. If triglycerides were $>400 \mathrm{mg} / \mathrm{dl}$, a direct LDL-C assay was utilized on the Siemans Dimension Vista. Parametric and non-parametric statistics were used as appropriate. The distribution of calcium scores was skewed, and therefore, medians and ranges are reported for this variable. The significance level was set at alpha $=0.05$. Calculations were done utilizing Social Statistics.com [17] and Good Calculators.com [18].

The University of New Mexico Institutional Review Board approved this study as a low risk, retrospective, observational study. As such, participant consent was not required.

\section{Results}

During the 5-year total observation period, 206 individuals requested a CAC scan. Of these individuals, 125 had a positive scan (Agatston score $>1$ ) and 81 had a negative scan ( $\leq 1$ score) (Figure 2$)$. The baseline demographics of these

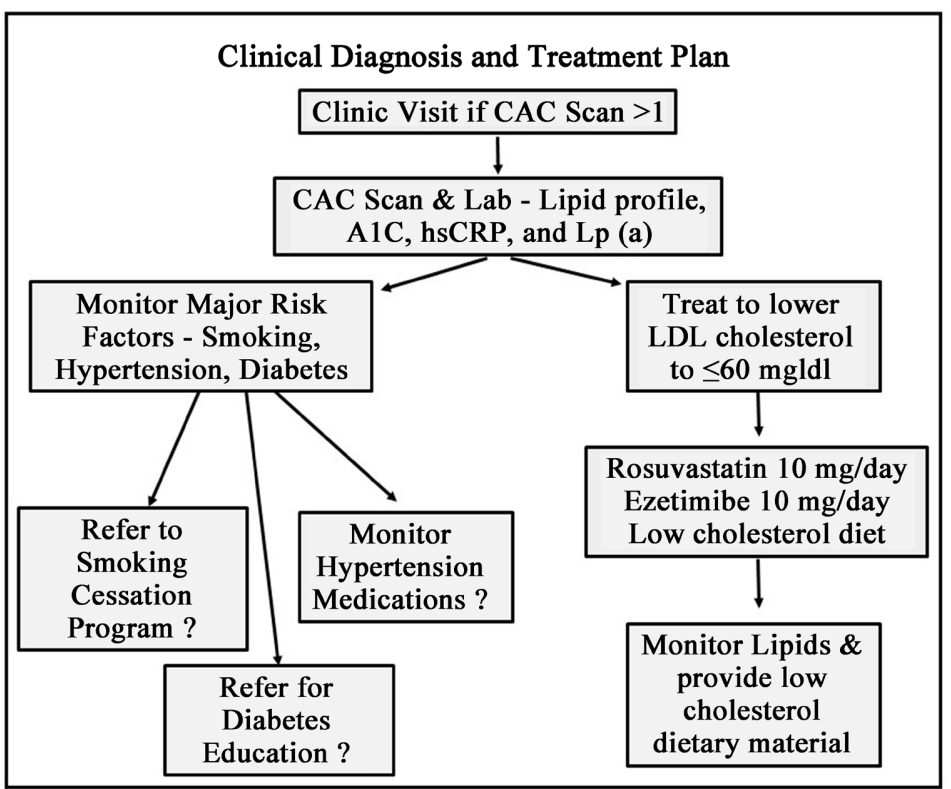

Abbreviations: $\mathrm{CAC}=$ coronary artery calcium scan; $\mathrm{A} 1 \mathrm{C}=$ hemoglobin $\mathrm{A} 1 \mathrm{C}$; hsCRP = high sensitivity $\mathrm{C}$ reactive protein; $\mathrm{Lp}(\mathrm{a})=$ lipoprotein $(\mathrm{a}) ; \mathrm{LDL}=$ low density lipoprotein.

Figure 2. Treatment plan for individuals with a positive CAC scan. Monitoring cardiovascular risk factors in addition to lipids. Follow current risk factor guidelines to achieve risk factor goals. First clinic visit following the initial visit was 2 months following the start of therapy. Subsequently, visits were scheduled at four to six month intervals. 
individuals are given in Table 2. Of note was the observation that significantly more females than males had a zero CAC score whereas just the opposite occurred for individuals with a positive CAC score $(\mathrm{p}<0.01)$. This may have been related, at least in part, to the significantly greater age in the positive CAC group compared with the zero CAC group $(\mathrm{p}<0.01)$. Thus, the positive CAC group had a longer exposure to noxious atherosclerotic risk factors compared with the zero CAC group. In spite of these differences, there was no significant difference between the three groups for any of the individual lipid values in the routine lipid profiles $(p>0.05)$. Furthermore, no significant differences were observed in the medical history of the following atherogenic risk factors in any of the three groups-diabetes, hypertension, smoking, and inflammation as assessed by high sensitivity C-reactive protein. However, the prevalence of the metabolic syndrome

Table 2. Baseline data for the individuals requesting a CAC scan.

\begin{tabular}{|c|c|c|c|c|}
\hline & $\begin{array}{c}\text { (a) }>1 \text { CAC score group } \\
\text { achieving } \mathrm{LDL}-\mathrm{C}<60 \mathrm{mg} / \mathrm{dl} \\
(\mathrm{N}=110)\end{array}$ & $\begin{array}{c}\text { (b) }>1 \text { CAC score group } \\
\text { not achieving LDL-C }<60 \\
\mathrm{mg} / \mathrm{dl}(\mathrm{N}=15)\end{array}$ & $\begin{array}{l}\text { (c) } \leq 1 \text { CAC score } \\
\text { group }(\mathrm{N}=81)\end{array}$ & Significance \\
\hline Gender & $\begin{array}{c}43 \text { female }(39 \%) \\
67 \text { male }(61 \%)\end{array}$ & $\begin{array}{l}4 \text { female }(27 \%) \\
11 \text { male }(73 \%)\end{array}$ & $\begin{array}{c}56 \text { female }(69 \%) \\
25 \text { male }(31 \%)\end{array}$ & $\begin{array}{c}\mathrm{P}<0.01 \\
\mathrm{P}=0.35 \text { (a vs. } \mathrm{b}) \\
\mathrm{P}<0.01 \text { (a vs. } \mathrm{c}) \\
\mathrm{P}<0.01 \text { (b vs. } \mathrm{c})\end{array}$ \\
\hline${ }^{\star}$ Median CAC score range ( ) & $204(5-3615)$ & $31(3-3614)$ & 0 & $\mathrm{P}<0.01$ \\
\hline Mean follow-up (years) & $3.5 \pm 0.18$ & $3.1 \pm 0.5$ & $3.8 \pm 0.3$ & $\mathrm{P}=0.72$ \\
\hline Age (years) & $66.5 \pm 0.85$ & $61.5 \pm 2.1$ & $57.8 \pm 1.2$ & $\begin{array}{c}\mathrm{P}<0.01 \\
\mathrm{P}=0.08 \text { (a vs. } \mathrm{b}) \\
\mathrm{P}<0.01 \text { (a vs. } \mathrm{c}) \\
\mathrm{P}=0.27 \text { (b vs. } \mathrm{c})\end{array}$ \\
\hline Total cholesterol mg/dl & $187 \pm 4.8$ & $216 \pm 11$ & ND & $\mathrm{P}=0.052$ \\
\hline HDL cholesterol mg/dl & $54.8 \pm 1.7$ & $59.2 \pm 4.6$ & ND & $\mathrm{P}=0.40$ \\
\hline Triglycerides mg/dl & $130 \pm 5.9$ & $115.8 \pm 27$ & ND & $\mathrm{P}=0.45$ \\
\hline LDL-C cholesterol mg/dl & $113 \pm 3.6$ & $129 \pm 11$ & ND & $\mathrm{P}=0.14$ \\
\hline $\mathrm{BMI} \mathrm{kg} / \mathrm{m}^{2}$ & $30.0 \pm 0.7$ & $27.1 \pm 1.2$ & ND & $\mathrm{P}=0.17$ \\
\hline Diabetes & $44 \%$ & $22.2 \%$ & ND & $\mathrm{P}=0.2$ \\
\hline Metabolic syndrome & $35 \%$ & $13 \%$ & ND & $\mathrm{P}<0.01$ \\
\hline History of smoking (\%) & $28 \%$ & $25 \%$ & ND & $\mathrm{P}=0.8$ \\
\hline Hypertension (\%) & $71 \%$ & $46 \%$ & ND & $\mathrm{P}=0.08$ \\
\hline hsCRP mg/L & $3.0 \pm 0.6$ & $2.6 \pm 0.8$ & ND & $\mathrm{P}=0.9$ \\
\hline
\end{tabular}

$\mathrm{ND}=$ no data. ${ }^{*}$ The Agatston CAC score is calculated using a weighted value assigned to the highest density of calcification in a given coronary artery. The density is measured in Hounsfield units, and score of 1 for 130 - 199 HU, 2 for 200 - 299 HU, 3 for 300 - $399 \mathrm{HU}$, and 4 for $400 \mathrm{HU}$ and greater. This weighted score is then multiplied by the area (in square millimeters) of the coronary calcification. The calcium score of every calcification in each coronary artery for all of the tomographic slices is then summed up to give the total coronary artery calcium score (CAC score). See Table 1 for additional explanation of diabetes and metabolic syndrome. The statistically significant items have been highlighted. 
was significantly greater for the group achieving an LDL-C of $\leq 60 \mathrm{mg} / \mathrm{dl}$ compared with the group that did not achieve this low LDL-C level $(\mathrm{p}<0.01)$. For the group with CAC scores of $\leq 1$, no patients were prescribed medical therapy. No cardiovascular events occurred in this group during follow-up.

In the group of 110 individuals who achieved an LDL-C $\leq 60 \mathrm{mg} / \mathrm{dl}$, Table 3 provides the changes in lipids and body mass index (BMI) that occurred by the patient's last visit compared with the baseline visit. Following specific medical therapy described above, LDL-C was reduced from $113 \mathrm{mg} / \mathrm{dl}$ to $49 \mathrm{mg} / \mathrm{dl}$, triglycerides decreased from $130 \mathrm{mg} / \mathrm{dl}$ to $100 \mathrm{mg} / \mathrm{dl}$ and HDL-C remained unchanged at $55 \mathrm{mg} / \mathrm{dl}$. In this group, the expected number of cardiovascular events was 12.6 . However, no cardiovascular events occurred. Two individuals in the LDL-C $\leq 60$ $\mathrm{mg} / \mathrm{dl}$ group died from non-cardiovascular causes, one in an automobile accident and one from Alzheimer's disease.

In the group with a positive CAC score that did not achieve an LDL-C $\leq 60$ $\mathrm{mg} / \mathrm{dl}$, two patients stopped medical therapy and subsequently each had a myocardial infarction. One patient died and one patient recovered. This latter patient subsequently required stenting for an acute coronary syndrome. In this small group of 15 individuals, the expected number of CVD events was $<1$.

\section{Discussion}

This study demonstrates that asymptomatic individuals with a positive CAC score, when treated with specific medical therapy to reduce their LDL-C $\leq 60 \mathrm{mg} / \mathrm{dl}$, do not experience overt cardiovascular disease events when followed for up to five years post-initiation of treatment. This is the first study (in a non-research setting) demonstrating that specific medical therapy in asymptomatic patients with proven subclinical cardiovascular disease directly benefits from lowering LDL-C below current guidelines. This observation is consistent with current literature emphasizing that LDL-C is a primary risk factor for atherosclerotic cardiovascular disease and that there is no lower threshold for the benefit [19]. In addition, unstable atherosclerotic plaques become stable within 30 days of statin therapy [20].

This study is unique in several ways. First, it is based upon a relatively unselected (there were no exclusions) asymptomatic adult clinic population requesting a coronary artery calcium scan. Second, the study employed specific medical

Table 3. Change in clinical parameters in the LDL-C $\leq 60 \mathrm{mg} / \mathrm{dl}$ group with $\mathrm{Rx}$.

\begin{tabular}{ccccc}
\hline Parameter & Avg. Prior to Rx & Avg. Post Rx & Difference & Significance \\
\hline Total-C mg/dl & $187 \pm 4.8$ & $128 \pm 3.1$ & -59 & $\mathrm{P}<0.01$ \\
HDL-C mg/dl & $54.8 \pm 1.7$ & $55.3 \pm 1.7$ & +0.5 & $\mathrm{P}=0.43$ \\
Triglycerides mg/dl & $130 \pm 5.9$ & $100 \pm 5.4$ & -30 & $\mathrm{P}<0.01$ \\
LDL-C mg/dl & $113 \pm 3.6$ & $49.0 \pm 1.4$ & -64 & $\mathrm{P}<0.01$ \\
BMI kg/m ${ }^{2}$ & $30.0 \pm 0.71$ & $29.0 \pm 0.72$ & -1 & $\mathrm{P}=0.4$ \\
\hline
\end{tabular}


therapy to achieve an LDL-C $\leq 60 \mathrm{mg} / \mathrm{dl}$ by using a combination of two LDL-C lowering medications plus a low cholesterol diet. Third, recommended lipid-lowering treatment was based solely on a positive coronary artery calcium score irrespective of the presence or absence of other cardiovascular risk factors. Fourth, in contrast to previous primary prevention statin research trials [21] [22] [23], treatment was associated with no cardiovascular events in the $\leq 60 \mathrm{LDL}-\mathrm{C}$ treatment $\mathrm{g}$ roup. It should be noted, however, that these statin trials did not use CAC testing to define asymptomatic CVD treatment.

Previous clinical trials have shown the potential for lipid-lowering therapy to influence CVD outcomes. In a study of 6595 men with moderate hypercholesterolemia and no history of myocardial infarction, treatment with pravastatin significantly reduced the incidence of myocardial infarction and death [21]. After an average follow-up of 5.2 years, in a study of 5608 men and 997 women with average total cholesterol and LDL-C levels and below-average HDL-C levels, lovastatin reduced the risk for the first acute major coronary event defined as fatal or nonfatal myocardial infarction, unstable angina, or sudden cardiac death [22]. In a more recent study (Hope-3) in 12,705 individuals at intermediate CVD risk, rosuvastatin at $10 \mathrm{mg} /$ day reduced CVD events from $4.8 \%$ to $3.7 \%$ [23]. As a potential mechanism for these results, regression of atherosclerosis has been demonstrated by several controlled clinical trials. The Asteroid Clinical Trial demonstrated that reduction of LDL-C levels below current guidelines when accompanied by an increase in HDL, can regress atherosclerosis in patients with coronary artery disease [24]. In a study comparing atorvastatin and rosuvastatin, both statins demonstrated atherosclerosis regression when the LDL- $C$ was reduced below $72 \mathrm{mg} / \mathrm{dl}$ [25]. These observations were further substantiated in a meta-analysis of 20 atherosclerosis regression trials with statins [26].

The decision to rely on the CAC score for treatment decisions and not on cardiovascular risk factors using a pooled cohort equation (e.g., the Framingham Risk Score) is based on numerous studies supporting CAC as a superior test. CAC is a better predictor of 10-year ASCVD risk than the pooled cohort equations [13]. In a study of 4864 patients, CAC scoring was the strongest predictor of death [27]. These studies support a paradigm shift in CVD risk assessment from a risk factor-based approach to detection of subclinical atherosclerosis with CAC testing [28]. Furthermore, a significant proportion of individuals with no risk factors may have a severe amount of coronary atherosclerosis and be at high risk for mortality [28]. The pooled cohort equations have difficulty accurately assessing the duration and intensity of risk factors [29] whereas CAC scoring represents the cumulative insults of all CVD risk factors that injure the endothelium and promote atherosclerotic plaques for the life of the patient [11]. CAC is similarly predictive of ASCVD in patients on or off statins [15]. CAC strongly predicts the risk of ASCVD with the same magnitude of effect in all races, age groups, and both sexes [15]. CAC testing is both financially and clinically effective as a risk stratification tool [30]. Finally, CAC improves compliance with statin therapy and weight loss 
motivation [31].

A positive coronary artery calcium score has limitations and is not always present in patients who experience acute coronary syndromes. In a study of patients with a history of acute myocardial infarction $(\mathrm{n}=101)$ and unstable angina $(\mathrm{n}=$ 17), patients with at least moderate angiographic disease had a positive CAC score (96\%). In the majority of these patients with negative CAC, the acute coronary syndrome was considered to be caused by mechanisms other than atherosclerosis (4 patients) or by focal atherosclerotic plaque formation (3 patients). Significant angiographic stenosis was observed in only 5 of 12 patients with negative CAC [32]. The reasons for a negative CAC (a zero score) in patients experiencing a cardiovascular event include: 1 ) the deposition of calcium in arterial vessels is a late occurring phenomenon (i.e., after initial plaque formation); 2) vessel occlusion can be caused by vasospasm; and 3) arterial obstruction by blood clot formation without plaque rupture can be secondary to endothelial dysfunction [33].

The current American Heart Association guidelines do not recommend treating asymptomatic patients to an LDL-C $<70 \mathrm{mg} / \mathrm{dl}$ unless they are considered "high risk" by one of the available risk calculators [34]. Although cardiac risk factors (e.g., smoking, hypertension, diabetes, and hyperlipidemia) increase the chances of a cardiovascular event, many CVD events occur in asymptomatic individuals with few risk factors. A coronary artery calcium scan provides an optimal, non-invasive approach to assessing the risk of a CVD event in most asymptomatic individuals. Its advantages include low cost, widespread availability, and minimal side effects. It has the potential for identifying the incidence of CVD in the general population (2) and has recently been recommended for being a preventative screening test, similar to colonoscopy [35].

The goal used for the treatment of a positive CAC scan of an LDL-C less than $60 \mathrm{mg} / \mathrm{dl}$ is based on several factors. First, it is achievable in the majority of patients. Ten $\mathrm{mg} /$ day of rosuvastatin will reduce basal cholesterol by approximately $40 \%$ [36]. The addition of ezetimibe at $10 \mathrm{mg} / \mathrm{d}$ will reduce LDL-C another $20 \%$ [37]. Finally, the addition of a low cholesterol diet will further reduce LDL-C [8] [38]. Second, an LDL-C of $60 \mathrm{mg}$ is safe and is similar to the LDL-C at birth [39]. No observed adverse effects have yet been observed with medication-induced very low LDL-C levels [40] [41]. Third, regression of atherosclerotic plaque in almost all individuals is anticipated since with an LDL-C $<78 \mathrm{mg} / \mathrm{dl}$, the majority of subjects with atherosclerosis regress their disease [24].

\section{Study Limitations}

There are several strengths and weaknesses to this study. First, it is retrospective, observational in design and the patients were not randomized to different cohorts. All patients were treated in a similar fashion if they had a positive coronary artery calcium score. Not all patients were compliant with treatment [42] and therefore, not all obtained an LDL-C $\leq 60 \mathrm{mg} / \mathrm{dl}$. However, these patients are sim- 
ilar to the type of patients that would be seen in a primary care setting. Second, the observation time may appear relatively short for the development of CVD but based on previously published data, there was ample time to observe significant numbers of cardiovascular events [15]. Third, there is no "control" placebotreated comparison group. The reason for this treatment decision is that it would be unethical not to offer treatment to all individuals with proven CVD. Fourth, the patients were all seen in a single health care medical clinic and our results may not be applicable to all clinics. However, none of the treatments were experimental and all were within the capability of general physician providers. Fifth, the "expected" CVD event rate was obtained from previously published populationbased studies. Our study's population is similar but not identical to these other published populations. However, all of these populations related their event rate to CAC scores.

In summary, this study demonstrates that it is feasible to significantly reduce the incidence of CVD by first ordering a CAC scan in individuals who are concerned with their CVD risk. Based on the CAC score, treatment of positive score individuals with rosuvastatin and ezetimibe plus a low cholesterol diet significantly reduces their risk of a cardiovascular event. In addition, a low dose of rosuvastatin and ezetimibe is acceptable and affordable therapy for most patients without incurring major adverse effects. Additional studies will be necessary to confirm our results and support the specific medical treatment of adults with positive CAC scans.

\section{Conflicts of Interest}

The authors declare no conflicts of interest regarding the publication of this paper.

\section{References}

[1] Benjamin, E.J., Virani, S.S., Callaway, C.W., Chamberlain, A.M., Chang, A.R., Cheng, S., et al. (2018) Heart Disease and Stroke Statistics-2018 Update: A Report from the American Heart Association. Circulation, 137, e67-e492. https://doi.org/10.1161/CIR.0000000000000573

[2] Schade, D.S. and Eaton, R.P. (2019) A Simplified Approach to Reducing Cardiovascular Risk. The Journal of Clinical Endocrinology \& Metabolism, 104, 6033-6039.

[3] Cholesterol Treatment Trialists' (CTT) Collaborators, Mihaylova, B., Emberson, J., Blackwell, L., Keech, A., Simes, J., Barnes, E.H., et al. (2012) The Effects of Lowering LDL Cholesterol with Statin Therapy in People at Low Risk of Vascular Disease: Meta-Analysis of Individual Data from 27 Randomised Trials. The Lancet, 380, 581-590. https://doi.org/10.1016/S0140-6736(12)60367-5

[4] Eaton, R.P., Burge, M.R., Comerci, G., Cavanaugh, B., Ramo, B. and Schade, D.S. (2016) Abnormal Coronary Artery Calcium Scans in Asymptomatic Patients. The American Journal of Medicine, 130, 394-397. https://doi.org/10.1016/j.amjmed.2016.10.006

[5] Miksenas, H., Januzzi, J.L. and Natarajan, P. (2021) Lipoprotein(a) and Cardiovascular Diseases. Journal of the American Medical Association, 326, 352-353. https://doi.org/10.1001/jama.2021.3632 
[6] Ridker, P.M. (2001) High-Sensitivity C-Reactive Protein: Potential Adjunct for Global Risk Assessment in the Primary Prevention of Cardiovascular Disease. Circulation, 103, 1813-1818. https://doi.org/10.1161/01.CIR.103.13.1813

[7] Min, J.K., Shaw, L.J., Devereux, R.B., Okin, P.M., Weinsaft, J.W., Russo, D.J., et al. (2007) Prognostic Value of Multidetector Coronary Computed Tomographic Angiography for Prediction of All-Cause Mortality. Journal of the American College of Cardiology, 50, 1161-1170. https://doi.org/10.1016/j.jacc.2007.03.067

[8] Schade, D.S., Gonzales, K., Kaminsky, N., Adolphe, A., Shey, L. and Eaton R.P. (2022) Resolving the Egg and Cholesterol Intake Controversy: New Clinical Insights into Cholesterol Regulation by the Liver and Intestine. Endocrine Practice, 28, 102-109. https://doi.org/10.1016/j.eprac.2021.09.004

[9] Baigent, C., Keech, A., Kearney, P.M., Blackwell, L., Buck, G., Pollicino, C. and The Cholesterol Treatment Trialists' (CTT) Collaborators (2005) Efficacy and Safety of Cholesterol-Lowering Treatment: Prospective Meta-Analysis of Data from 90,056 Participants in 14 Randomised Trials of Statins. The Lancet, 366, 1267-1278. https://doi.org/10.1016/S0140-6736(05)67394-1

[10] Al Rifai, M., Cainzos-Achirica, M. and Blaha, M.J. (2015) Establishing the Warranty of a Coronary Artery Calcium Score of Zero. Atherosclerosis, 238, 1-3. https://doi.org/10.1016/j.atherosclerosis.2014.10.084

[11] Callister, T.Q., Raggi, P., Cooil, B., Lippolis, N.J. and Russo, D.J. (1998) Effect of HMGCoA Reductase Inhibitors on Coronary Artery Disease as Assessed by Electron-Beam Computed Tomography. The New England Journal of Medicine, 339, 1972-1978. https://doi.org/10.1056/NEJM199812313392703

[12] Hecht, H., Blaha, M.J., Berman, D.S., Nasir, K., Budoff, M., Leipsic, J., et al. (2017) Clinical Indications for Coronary Artery Calcium Scoring in Asymptomatic Patients: Expert Consensus Statement from the Society of Cardiovascular Computed Tomography. Journal of Cardiovascular Computed Tomography, 11, 157-168. https://doi.org/10.1016/j.jcct.2017.02.010

[13] Vliegenthart, R., Oudkerk, M., Hofman, A., et al. (2005) Coronary Calcification Improves Cardiovascular Risk Prediction in the Elderly. Circulation, 112, 572-577. https://doi.org/10.1161/CIRCULATIONAHA.104.488916

[14] Budoff, M.J., Young, R., Burke, G., Carr, J.J., Detrano, R.C., et al. (2018) Ten-Year Association of Coronary Artery Calcium with Atherosclerotic Cardiovascular Disease (ASCVD) Events: The Multi-Ethnic Study of Atherosclerosis (MESA). European Heart Journal, 39, 2401-2408. https://doi.org/10.1093/eurheartj/ehy217

[15] Malik, S., Budoff, M.J., Katz, R., Blumenthal, R.S., Bertoni, A.G., Nasir, K., Szklo, M., Barr, R.G. and Wong, N.D. (2011) Impact of Subclinical Atherosclerosis on Cardiovascular Disease Events in Individuals with Metabolic Syndrome and Diabetes. Diabetes Care, 34, 2285-2290. https://doi.org/10.2337/dc11-0816

[16] Mora, S., Rifai, N., Buring, J.E. and Ridker, P.M. (2009) Comparison of LDL Cholesterol Concentrations by Friedewald Calculation and Direct Measurement in Relation to Cardiovascular Events in 27,331 Women. Clinical Chemistry, 55, 888-894. https://doi.org/10.1373/clinchem.2008.117929

[17] Stangroom, J. (2018) Social Science Statistics. https://www.socscistatistics.com

[18] Sanders, J. and Stacy, A. (2021) Good Calculators: Free Online Calculators. https://goodcalculators.com

[19] Schade, D.S., Cavanaugh, B., Ramo, B. and Eaton, R.P. (2016) The Application of the LDL Principle. World Journal of Cardiovascular Diseases, 6, 109-125. 
https://doi.org/10.4236/wjcd.2016.65012

[20] Nakamura, T., Obata, J.E., Kitta, Y., Takano, H., Kobayashi, T., Fujioka, D., Saito, Y., Kodama, Y., Kawabata, K., Mende, A., Yano, T., Hirano, M., Sano, K., Nakamura, K., Kugiyama, K., et al. (2008) Rapid Stabilization of Vulnerable Carotid Plaque within 1 Month of Pitavastatin Treatment in Patients with Acute Coronary Syndrome. Journal of Cardiovascular Pharmacology, 51, 365-371. https://doi.org/10.1097/FJC.0b013e318165dcad

[21] Shepherd, J., Cobbe, S.M., Ford, I., Isles, C.G., Lorimer, A.R., MacFarlane, P.W., et al. (1995) Prevention of Coronary Heart Disease with Pravastatin in Men with Hypercholesterolemia. The New England Journal of Medicine, 333, 1301-1308. https://doi.org/10.1056/NEJM199511163332001

[22] Downs, J.R., Clearfield, M., Weis, S., Whitney, E., Shapiro, D.R., Beere, P.A., et al. (1998) Primary Prevention of Acute Coronary Events with Lovastatin in Men and Women with Average Cholesterol Levels: Results of AFCAPS/TexCAPS Research. Journal of the American Medical Association, 279, 1615-1622. https://doi.org/10.1001/jama.279.20.1615

[23] Yusuf, S., Bosch, J., Dagenais, G., Zhu, J., Xavier, D., Liu, L., The HOPE-3 Investigators, et al. (2016) Cholesterol Lowering in Intermediate-Risk Persons without Cardiovascular Disease. The New England Journal of Medicine, 374, 2021-2031.

https://doi.org/10.1056/NEJMoa1600176

[24] Nissen, S.E., Nicholls, S.J., Sipahi, I., Libby, P., Raichlen, J.S., Ballantyne, C.M., Davignon, J., Erbel, R., Fruchart, J.C., Tardif, J.C., Schoenhagen, P., Crowe, T., Cain, V., Wolski, K., Goormastic, M., Tuzcu, E.M., The ASTEROID Investigators, et al. (2006) Effect of very High-Intensity Statin Therapy on Regression of Coronary Atherosclerosis-The ASTEROID Trial. Journal of the American Medical Association, 295, 15561565. https://doi.org/10.1001/jama.295.13.jpc60002

[25] Nicholls, S.J., Ballantyne, C.M., Barter, P.J., Chapman, J., Erbel, R.M., Libby, P., et al. (2011) Effect of Two Intensive Statin Regimens on Progression of Coronary Disease. The New England Journal of Medicine, 365, 2078-2087. https://doi.org/10.1056/NEJMoa1110874

[26] Gao, W.Q., Feng, Q.Z., Li, Y.F., Li, Y.X., Huang, Y., Chen, Y.M., et al. (2014) Systematic Study of the Effects of Lowering Low-Density Lipoprotein-Cholesterol on Regression of Coronary Atherosclerotic Plaques Using Intravascular Ultrasound. BMC Cardiovascular Disorders, 14, Article No. 60.

https://doi.org/10.1186/1471-2261-14-60

[27] Valenti, V., Hartaigh, B.O., Heo, R., Cho, I., Schulman-Marcus, J., Gransar, H., et al. (2015) A 15-Year Warranty Period for Asymptomatic Individuals without Coronary Artery Calcium. JACC: Cardiovascular Imaging, 8, 900-909. https://doi.org/10.1016/j.jcmg.2015.01.025

[28] Nasir, K., Rubin, J., Blaha, M.J., Shaw, L.J., Blankstein, R., Rivera, J.J., et al. (2012) Interplay of Coronary Artery Calcification and Traditional Risk Factors for the Prediction of All-Cause Mortality in Asymptomatic Individuals. Circulation: Cardiovascular Imaging, 5, 467-473. https://doi.org/10.1161/CIRCIMAGING.111.964528

[29] Blaha, M.J., Silverman, M.G. and Budoff, M.J. (2014) Is there a Role for Coronary Artery Calcium Scoring for Management of Asymptomatic Patients at Risk for Coronary Artery Disease? Clinical Risk Scores Are Not Sufficient to Define Primary Prevention Treatment Strategies among Asymptomatic Patients. Circulation: Cardiovascular Imaging, 7, 398-408. https://doi.org/10.1161/CIRCIMAGING.113.000341

[30] Roberts, E.T., Horne, A., Martin, S.S., Blaha, M.J., Blankstein, R., Budoff, M.J., et al. (2015) Cost-Effectiveness of Coronary Artery Calcium Testing for Coronary Heart and Cardiovascular Disease Risk Prediction to Guide Statin Allocation: The Multi-Eth- 
nic Study of Atherosclerosis (MESA). PLoS ONE, 10, e0116377. https://doi.org/10.1371/journal.pone.0116377

[31] Kalia, N.K., Cespedes, L., Youssef, G., Li, D. and Budoff, M.J. (2015) Motivational Effects of Coronary Artery Calcium Scores on Statin Adherence and Weight Loss. Coronary Artery Disease, 26, 225-230. https://doi.org/10.1097/MCA.0000000000000207

[32] Schmermund, A., Baumgart, D., Gorge, G., Seibel, R., Gronemeyer, D., et al. (1997) Coronary Artery Calcium in Acute Coronary Syndromes: A Comparative Study of Electron-Beam Computed Tomography, Coronary Angiography, and Intracoronary Ultrasound in Survivors of Acute Myocardial Infarction and Unstable Angina. Circulation, 96, 1461-1469. https://doi.org/10.1161/01.CIR.96.5.1461

[33] Braunwald, E. (2013) Coronary Plaque Erosion: Recognition and Management. JACC: Cardiovascular Imaging, 6, 288-289. https://doi.org/10.1016/j.jcmg.2013.01.003

[34] Arnett, D.K., Blumenthal, R.S., Albert, M.A., Michos, E.D., Buroker, A.B., Miedema, M.D., et al. (2019) 2019 ACC/AHA Guideline on the Primary Prevention of Cardiovascular Disease: A Report of the American College of Cardiology/American Heart Association Task Force on Clinical Practice Guidelines. Journal of the American College of Cardiology, 74, e177-e232. https://doi.org/10.1016/j.jacc.2019.03.010

[35] Schade, D.S., Arora, S. and Eaton, R.P. (2020) Should Routine Screening for Coronary Artery Disease Be Recommended? A Comparison with Routine Screening for Colon Cancer. The American Journal of Medicine, 133, 155-157.

[36] Olsson, A.G., Pears, J., McKellar, J., Mizan, J. and Raza, A. (2001) Effect of Rosuvastatin on Low-Density Lipoprotein Cholesterol in Patients with Hypercholesterolemia. The American Journal of Cardiology, 88, 504-508.

[37] Gagné, C.G., Bays, H.E., Weiss, S.R., Mata, P., Quinto, K., Melino, M., The Ezetimibe Study Group, et al. (2002) Efficacy and Safety of Ezetimibe Added to Ongoing Statin Therapy for Treatment of Patients with Primary Hypercholesterolemia. The American Journal of Cardiology, 90, 1084-1091.

[38] Schonfeld, G., Patsch, W., Rudel, L.L., Nelson, C., Epstein, M. and Olson, R.E. (1982) Effects of Dietary Cholesterol and Fatty Acids on Plasma Lipoproteins. Journal of Clinical Investigation, 69, 1072-1080. https://doi.org/10.1172/JCI110542

[39] O’Keefe, J.H., Cordain, L., Harris, W.H., Moe, R.M. and Vogel, R. (2004) Optimal LowDensity Lipoprotein Is 50 to $70 \mathrm{mg} / \mathrm{dl}$ : Lower Is Better and Physiologically Normal. Journal of the American College of Cardiology, 43, 2142-2146. https://doi.org/10.1016/j.jacc.2004.03.046

[40] Karagiannis, A.D., Mehta, A., Dhindsa, D.S., Virani, S.S., Orringer, C.E., et al. (2021) How Low Is Safe? The Frontier of very Low $(<30 \mathrm{mg} / \mathrm{dL})$ LDL Cholesterol. European Heart Journal, 42, 2154-2169. https://doi.org/10.1093/eurheartj/ehaa1080

[41] Collins, R., Reith, C., Emberson, J., Armitage, J., Baigent, C., et al. (2016) Interpretation of the Evidence for the Efficacy and Safety of Statin Therapy. The Lancet, 388, 2532-2561. https://doi.org/10.1016/S0140-6736(16)31357-5

[42] Kataoka, Y., John, J., Wolski, K., Uno, K., Puri, R., Tuzcu, E.M., Nissen, S.E. and Nicholls, S.J. (2015) Atheroma Progression in Hyporesponders to Statin Therapy. Arteriosclerosis, Thrombosis, and Vascular Biology, 35, 990-995.

https://doi.org/10.1161/ATVBAHA.114.304477 